\title{
DIET MODULATION RESTORES AUTOPHAGIC FLUX IN DAMAGED SKELETAL MUSCLE CELLS
}

\author{
F.M. GIORDANO ${ }^{1}$, S. BURATTINI ${ }^{1}$, F. BUONTEMPO ${ }^{2}$, B. CANONICO ${ }^{1}$, A.M. MARTELLI ${ }^{2}$, S. \\ PAPA $^{1}$, M. SAMPAOLESI ${ }^{3,4}$, E. FALCIERI ${ }^{1}$, S. SALUCCI ${ }^{1}$
}

1. Department of Biomolecular Sciences, University of Urbino Carlo Bo, Urbino, Italy; 2. Department of Biomedical and Neuromotor Sciences, University of Bologna, Bologna, Italy; 3. Translational Cardiomyology Laboratory, Stem Cell Institute of Leuven, Unit of Stem Cell Research, Cluster of Stem Cell and Developmental Biology, Department of Development and Regeneration, University of Leuven, Leuven, Belgium; 4. Human Anatomy Unit, Department of Public Health, Experimental and Forensic Medicine, University of Pavia, Pavia,

Italy. Corresponding author: Sara Salucci, Department of Biomolecular Sciences, University of Urbino Carlo Bo, Urbino, Italy, Email: sara.salucci@uniurb.it

\begin{abstract}
Objectives: Autophagy is a physiological and highly regulated mechanism, crucial for cell homeostasis maintenance. Its impairment seems to be involved in the onset of several diseases, including muscular dystrophies, myopathies and sarcopenia. According to few papers, chemotherapeutic drug treatment is able to trigger side effects on skeletal muscle tissue and, among these, a defective autophagic activation, which leads to the persistence of abnormal organelles within cells and, finally, to myofiber degeneration. The aim of this work is to find a strategy, based on diet modulation, to prevent etoposide-induced damage, in a model of in vitro skeletal muscle cells. Methods: Glutamine supplementation and nutrient deprivation have been chosen as pre-treatments to counteract etoposide effect, a chemotherapeutic drug known to induce oxidative stress and cell death. Cell response has been evaluated by means of morpho-functional, cytofluorimetric and molecular analyses. Results: Etoposide treated cells, if compared to control, showed dysfunctional mitochondria presence, ER stress and lysosomal compartment damage, confirmed by molecular investigations. Conclusions: Interestingly, both dietary approaches were able to rescue myofiber from etoposide-induced damage. Glutamine supplementation, in particular, seemed to be a good strategy to preserve cell ultrastructure and functionality, by preventing the autophagic impairment and partially restoring the normal lysosomal activity, thus maintaining skeletal muscle homeostasis.
\end{abstract}

Key words: Skeletal muscle cells, chemotherapy treatment, mitochondria dysfunctionality, ER stress, lysosomal activity.

\section{Introduction}

In skeletal muscle, cell homeostasis is ensured by two different pathways, which can be considered as "survival mechanisms": the ubiquitin-proteasome system and the autophagy-lysosome system. These two proteolytic pathways are highly regulated and involved in muscle atrophy occurrence (1).

In particular, the autophagy-lysosome signaling seems to be crucial for removing dysfunctional organelles and unfolded proteins, thus preventing their accumulation within the cell. On the other hand, the ubiquitin-proteasome system is responsible for protein quality control (2) both under normal and pathological conditions (3). In recent years, researchers focused their attention on the relationship between autophagy and disease. Indeed, an autophagic flux impairment seems to be involved in the onset of several pathologies $(4,5)$ such as muscular dystrophies and myopathies $(6,7)$, cancer $(8,9)$, diabetes (10), Parkinson's, Alzheimer's, Huntington's disease (11) and LSDs - lysosomal storage disorder's (12). According to few papers in the literature, chemotherapeutic treatments are able to trigger skeletal muscle damage $(13,14)$.

Moreover, we and others have previously demonstrated that $\mathrm{C} 2 \mathrm{C} 12$ myotubes treated with $\mathrm{e}$ toposide (Eto), a chemotherapeutic drug known to induce cell death and oxidative stress increase, undergo nuclear disruption,

Received February 2, 2019 cytoplasmic shrinkage, organelle alterations (15-17) as well as functional muscle impairment $(18,19)$.

Therefore, to find new therapeutic strategies to counteract muscle damage induced by chemotherapeutic drug exposure, based on diet modulation, could represent an interesting investigation field for many researchers to prevent muscle wasting observed in cancer-treated patients.

Glutamine, a non-essential branched-chain amino acid, seems to exert a protective role in skeletal muscle cells exposed to stress-inducing triggers (20-22). On the other hand, nutrient deprivation could represent a possible way to reactivate a protective role of autophagy, as already described by De Palma et al., 2014 (23) in a murine muscular dystrophic model.

Here, an in vitro skeletal muscle cell line has been exposed to Eto, to mimic chemotherapeutic induced damage. To counteract Eto effects, glutamine supplementation (iperglut) and nutrient deprivation have been evaluated as protective pretreatments before drug exposure. Morpho-functional, cytofluorimetric and molecular analyses have been carried out to confirm Eto toxicity and to verify if diet modulation could prevent Eto-induced damage in differentiated $\mathrm{C} 2 \mathrm{C} 12$ cells. 


\section{Materials and Methods}

\section{Cell Culture and treatments}

$\mathrm{C} 2 \mathrm{C} 12$ differentiated cells were grown in flasks or on coverslips in dishes as previously described (15). Upon reaching approximately $80 \%$ of confluence, myotube formation was induced with differentiation medium (DM) as described by (24).

Cells were maintained at $37^{\circ} \mathrm{C}$ in hwnidified atmosphere with $5 \% \mathrm{CO}_{2}$, daily monitored with a Nikon Eclipse TE 2000$S$ inverted Microscope (IM) and photographed with a digital DN 100 Nikon system (25). Cells were processed for electron, confocal microscopy as well as for flow cytometric and molecular analyses at the end of the 7th day of differentiation (26)

\section{Cell treatments}

Cell damage was induced by exposing myotubes to $50, u / v l$ Eto for $24 \mathrm{~h}$ at the end of the 6th day of differentiation. Drug concentration was chosen on the basis of previous findings by om group $(15,17,27)$.

Moreover, to cmmteract Eto induced damage, iperglut and $4 \mathrm{~h}$ starvation were the chosen treatments.

In particular, iperglut condition was carried out doubling the glutamine percentage in the medium ( $2 \%$ instead of the standard $1 \%$ ) and administrated it to cell culture starting from 0 day nntil 7 days of differentiation.

4h starvation was pert'ormed with the glutamine-free mediwn and serum. Cells at 6 days of differentiation were incubated with serum and glutamine free medium for $4 \mathrm{~h}$ and then refreshed with complete medium until 7 days of differentiation.

\section{Transmission Electron Microscopy (I'EM)} TEM.

Both pellets and monolayers were analysed by means of

Samples were grown in flasks to get pellets and on coverslips in dishes to obtain monolayers. In both cases, specimens were rinsed with PBS and immediately fixed in situ with $2.5 \%$ glutaraldyde in $0.1 \mathrm{M}$ phosphate buffer for 45 minutes. Cells were gently scraped after 15 minutes and then centrifuged at $1200 \mathrm{rpm}$ for 30 minutes (28). Post-fixation in $1 \% \mathrm{OsO}_{4}$ for $1 \mathrm{~h}$, alcohol dehydration and araldite inclusion were performed, as previously desclibed (27). Monolayer embedding was carried out by inverting capsules full of resin on samples; coverslips were then removed in liquid nitrogen (17).

After uranyl acetate and lead citrate staining, thin sections ( $0.5 \mathrm{Jlm}$ ) were observed by means of electron microscope.

\section{Immunofluorescence analysis (IF)}

Cells were grown in a 12-well plate, fixed with $4 \%$ paraformaldehyde (PFA) in PBS for 15 minutes in the dark, rinsed with PBS and stored at $4{ }^{\circ} \mathrm{C}$ nntil immnnostaining,

Samples were permeabilized with $0.2 \%$ Triton X-100 in PBS, containing $1 \%$ bovine serwn albumin (BSA). Donkey serum (1:10 dilution in PBS) was applied as blocking solution and specimens were incubated with primary antibodies (reported hereafter) overnight in PBS $+1 \%$ BSA (29). Alexa Fluor-conjugated secondary donkey antibodies were used 1:500 in PBS supplemented with $1 \%$ BSA and the nuclei were stained with Hoechst 33342 (Sigma Aldrich, 1:3000 in PBS) Images were collected using an Eclipse Ti inverted microscope (Nikon).

Primary antibodies and their dilutions were as follows: 1:4 mouse anti-MyHC (Developmental Studies Hybridoma Bank. DSHB, clone MF20), 1:300 mouse anti-ki67 (Abeam), 1:50 rabbit anti MyoD (Abeam)

\section{Flow Cytometry $(F C)$}

The cardiolipin sensitive probe (NAO; Sigma Aldrich) is able to monitor changes in mitochondrial lipids $(15,30,31)$ and used at low concentrations, in living cells. It is an efficient fluorescent indicator for the peroxidation of cardiolipin, an inner mitochondrial membrane lipid. Cells were incubated with 150ni'vf NAO for 15 minutes at $37^{\circ} \mathrm{C}$ in the dark and then acquired by $\mathrm{FC}$ using the appropriate fluorescence channels. 10,000 events for each condition were analyzed (16).

The tetramethylrhodamine ethyl ester (Tlv!RE) has been used to focus on mitochondria functional status thank to its ability to selectively enter into mitochondria according to the Nemst equation $(32,33)$. Cells have been loaded with 40 nlvl TMRE at $37^{\circ} \mathrm{C}$ for 15 minutes and the analysis has been carried out nnder non-quenching conditions. The specificity of this analysis has been detemlined using the 1 mcoupling agent CCCP (SigmaAldrich) which caused mitochondrial membrane depolarization with a sudden decrease of $\mathrm{Tl}$ "dRE fluorescence. Cells have been treated for 30 minutes with $10 \mathrm{mM} \mathrm{CCCP}$, stained with TMRE is described, and then acquired by flow cytometry. Fluorescence intensity as the initial signal after background subtraction.

The endoplasmic reticulum (ER) stress has been detected by means of ER-Tracker Green (Thermo Fisher Scientific, Waltham, MA, USA). This is a live-cell stain highly selective for the ER. This stain consists of the green fluorescent BODIPY ${ }^{\circledR}$ FL dye and glibenclamide that binds to the sulphonylurea receptors of ATP-sensitive $\mathrm{K}+$ channels which are prominent on the ER and have a critical role in ER luminal homeostasis. Indeed. ER $\mathrm{K}+$ channels are involved in fnnctions such as protein folding, apoptosis, and calcium homeostasis $(34,35)$. Cells have been incubated with 100 nlvl ERTracker Green for 30 minutes at $37 \mathrm{oc}$ and subjected to flow cytometric analyses.

The Acridine Orange (AO) is a $\mathrm{pH}$ sensitive dye, used to detect acidic vesicular organelle formation (36-38). Cells were washed and resuspendend in $0.5 \mathrm{ml}$ of medium and then stained with AO $75 \mathrm{ng} / \mathrm{ml}, 15$ minutes at $37^{\circ} \mathrm{C}$ Red lysosomal and green cytoplasmatic fluorescences of 10,000 cells per sample were acquired by FC using the FL3 and FL:1 channels respectively. 
Cells were grown, treated and processed for observations on coverslips in a 6-well plate.

Premo $^{\mathrm{TM}}$ Autophagy Sensor LC3-GFP (Thermo Fisher Scientific) allows to detect the LC3 protein localization; cells were transduced following the protocol provided by the datasheet $(\mathrm{Exc} / \mathrm{Em}=488 / 520)$.

$500 \mathrm{ng} / \mathrm{ml} \mathrm{AO}$ were added directly to culture medium for 15 minutes at $37^{\circ} \mathrm{C}(39)$.

Observations were performed with a Leica TCS-SP5 confocal microscope, connected to a DMI 6000 CS Inverted Microscope (Leica Microsystems CMS Gmbh); pictures were analyzed using the Leica Application Suite Advanced Fluorescence (LAS AF) software (26).

\section{Western Blotting}

Protein assay was performed using the Bio-Rad protein assay according to the manufacturer's instructions. Cells were lysed at $107 / \mathrm{ml}$ in RIPA lysis buffer containing the Complete Protease Inhibitor Cocktail (Thermo Fisher Scientific Inc., Rockford, IL, USA). Lysates were then briefly sonicated to shear DNA and reduce viscosity and boiled for 5 minutes with reducing sample buffer. Gradient gels (4\%-20\% acrylamide) were used (Bio-Rad, Hercules, CA, USA). Analysis with an antibody to $\beta$-actin documented equal protein loading. All the primary and secondary antibodies were from Cell Signaling Technology (Danvers, MA, USA). Proteins were detected using the ECL Westar $\eta \mathrm{C} 2.0$ reagent (Cyanagen, Bologna, Italy). The ChemiDoc-It2 Imaging System and the VisionWorksLS Software (UVP, LLC, Upland, CA, USA) were used to achieve images (39).

\section{Results}

Control myotubes were multinucleated and revealed the presence of several long shaped mitochondria, organized myofibers and, occasionally, autophagic vacuoles (Fig. 1A-D). The evaluation of Myosin Heavy-Chain (MyHC) by means of IF staining, evidenced preserved control fibers with a typical elongated shape (Fig.1D). Fusion index, calculated on the basis of the ratio between the number of nuclei within myotubes and the total number of nuclei in a field, was about $60 \%$ (Fig. 1K), in agreement with others (40).

Cells treated with iperglut (Fig. 1E, G) or starvation (Fig. 1H, I) showed a preserved architecture with numerous mitochondria. Autophagic vacuoles were also observable, especially after starvation treatment.

Iperglut- (Fig.1F) or starvation (Fig.1J) -treated myotubes showed a morphology similar to control with a fusion index about of $\sim 66 \%$ and $54 \%$ respectively (Fig. $1 \mathrm{~K}$ ).

Eto-treated fibers evidenced a diffuse damage characterized

be observed. In this experimental condition, IF revealed by cytoplasmic vacuolization (Fig. 2A), mitochondria alterations (Fig. 2C) and ER stress; the presence of abnormal autophagic structures, even as big as myonuclei, is observable (Fig. 2A, 2E, 2F). These mega-vacuoles sometimes were empty (Fig. 2G), with an evident cytoplasmic shrinkage which leaded, as a consequence, to a reduced fiber size and to myofiber degeneration.

Figure 1

Control (A-D), iperglut (E-G) and starved myotubes (H-J) observed at TEM (A-C, E, G, H, I) and at IF (D, F and J)

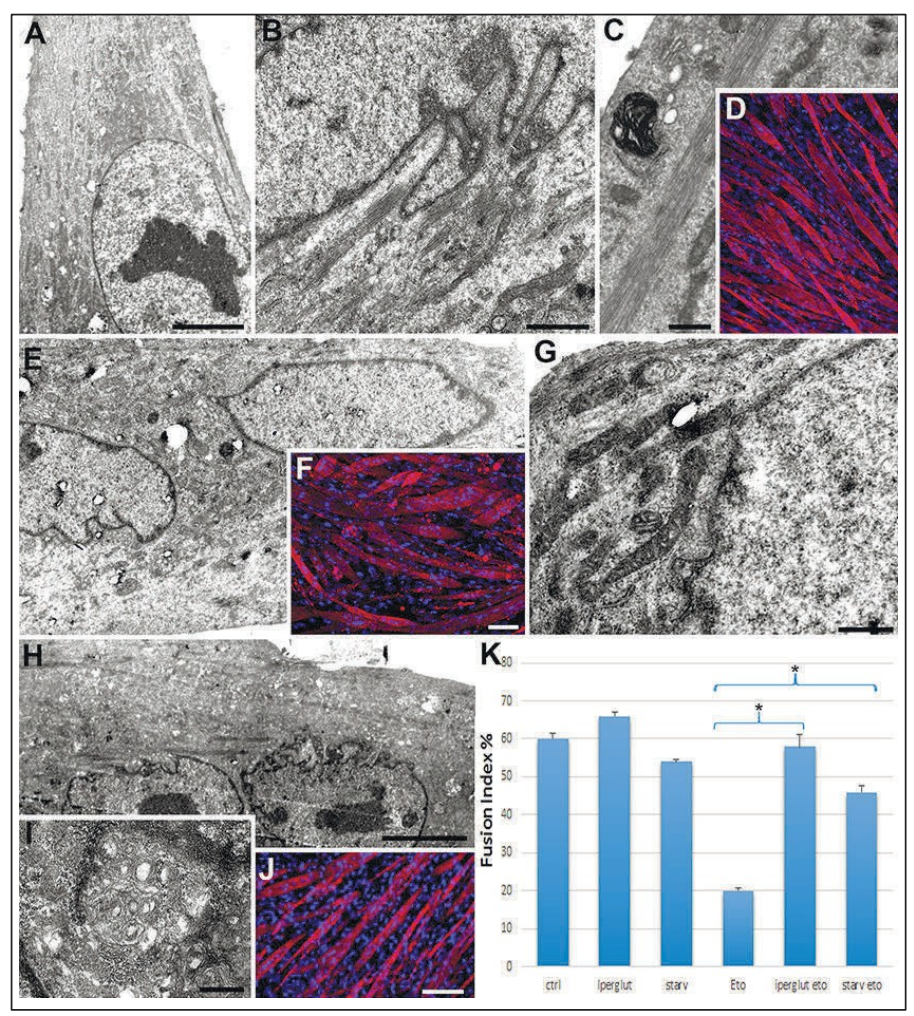

Micrographs show multinucleated cells with preserved mitochondria and cytoplasmic components. Sometimes autophagic vacuoles can be observed, particularly after starvation treatment. In $\mathrm{K}$, the calculated fusion index of all experimental conditions is shown, expressed as mean \pm SD. For statistical analysis, Student t-test has been carried out. Both pre-treatments before drug vs Eto- treated myotubes are significant $(* p<0.05)$. Bars: 100 $\mu \mathrm{m}$ for $\mathrm{D}, \mathrm{F}, \mathrm{J} ; 5 \mu \mathrm{m}$ for $\mathrm{A}$ and $\mathrm{H}, 1 \mu \mathrm{m}$ for $\mathrm{B} ; 0.5 \mu \mathrm{m}$ for $\mathrm{C}, \mathrm{G}$ and $\mathrm{I}$.

This behavior has been confirmed by IF staining. Eto-treated cells, indeed, displayed a strong reduction in terms of myotube number, which appeared small and thin (Fig.2B) with fusion index reduced to $20 \%$ or even less (Fig. $1 \mathrm{~K}$ ).

Iperglut pre-treatment, before Eto exposure, improved myotube morphology (Fig. 3A, C) if compared to Eto-treated cells; ER was similar to control and most of mitochondria appeared preserved. This morphology could be observed after IF too (Fig. 3B), where the calculated fusion index was about $58 \%$, a percentage similar to control (Fig. $1 \mathrm{~K}$ ).

Starved cells, before Eto administration (Fig. 3D-F), retained their shape even if a diffuse cytoplasmic vacuolization, altered mitochondria and a conspicuous autophagic activation could 
calculated fusion index of about $46 \%$ (Fig. 1K).

Figure 2

Eto-treated myotubes observed by TEM (A, C-G) and IF (B)

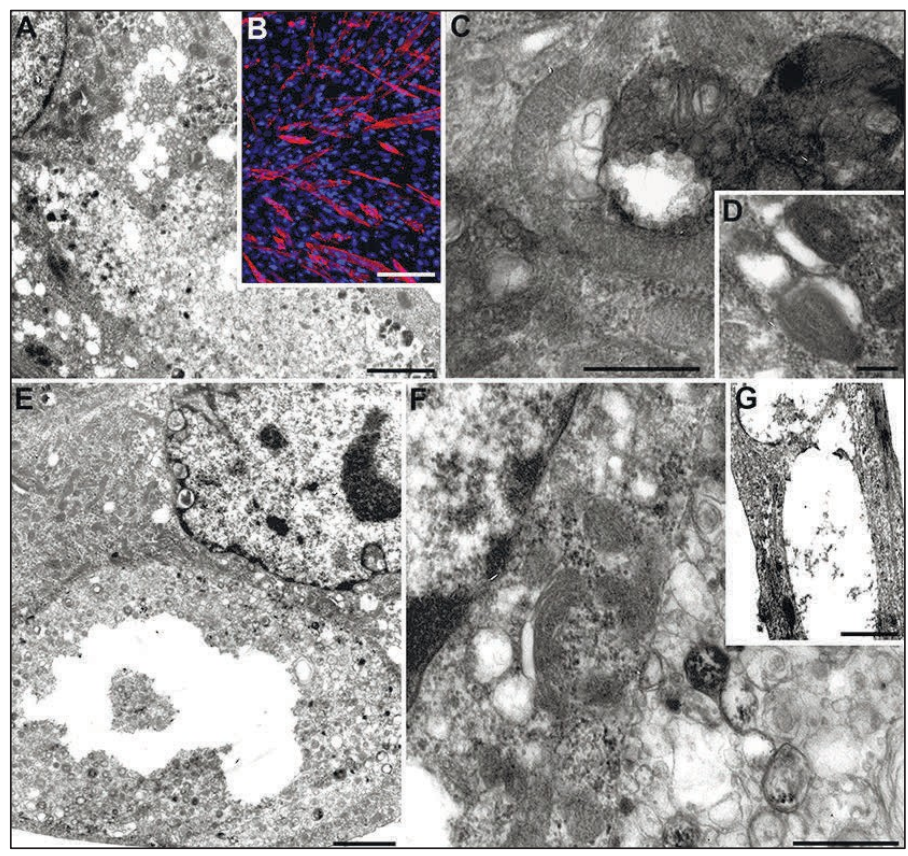

Cells display an evident damage of mitochondria and ER as well as the presence of abnormal vacuoles. IF analysis shows a reduced myotube size and number. Bars: $2 \mu \mathrm{m}$ for A, E, G; $50 \mu \mathrm{m}$ for B; $200 \mathrm{~nm}$ for $\mathrm{C} ; 500 \mathrm{~nm}$ for $\mathrm{C}, \mathrm{F}$.

According to ultrastructural observations, FC analyses showed functional mitochondria in control condition and after iperglut supplementation. The presence of damagedmitochondria could be observed after Eto administration, a chemotherapeutic agent able to activate also an oxidative pathway, as already reported by Salucci et al., 2013, 2016, 2017 (15-17). In this experimental condition, a high number of peroxidation events has been quantified by means of NAO staining (Fig $3 \mathrm{H}$ ) and the analysis of TMRE/MTG ratio showed the presence of inactive and disrupted mitochondria (Fig. 3I). Iperglut or starvation administration before drug treatment reduced the presence of peroxidated cardiolipin and decreased TMRE/MTG ratio, suggesting that both pre-treatments were able to preserve mitochondrial viability.

Moreover, ER, the major site for the synthesis, folding and trafficking of secretory and membrane proteins, is known to be highly sensitive to redox status (41).

Here, ER state has been evaluated through FC, showing a MFI fluorescence increase (Fig. 3J) in case of starved and Etotreated cells, if compared with other conditions. Dilated ER, absent in control condition (Fig. 3K), has been also observed after Eto exposure at TEM (Fig. 3L). Both pre-treatments, in particular iperglut, restored ER functionality (Fig. 3J) and morphology (Fig. 3M).

It is known that ER stress leads to activation of unfolded protein response (UPR) that acts as adaptive mechanisms to re-establish protein homeostasis (42). However, when the accumulation of unfolded/misfolded proteins occurs, Grp78/BiP, a major ER chaperone protein, critical for ER protein quality control, preferentially binds these proteins. As a consequence, ER stress response activation, including an up-regulation of genes encoding Grp78/BiP and a downregulation of protein synthesis, occurs $(43,44)$. In this study, WB analysis (Fig. $3 \mathrm{~N}$ ) revealed that after starvation and Eto treatment, Grp78/BiP expression markedly increased compared with the other experimental conditions, for activating UPR, probably as an attempt to facilitate proper folding of misfolded proteins or to contribute to cell death.

Figure 3

Iperglut (A-C) and starved-myotubes (D-G) after TEM (A, $\mathrm{C}-\mathrm{F})$ and IF (B, G) observations. Both pre-treatments improve myotube morphology, which appears similar to control condition. Mitochondria (H, I) and ER (J) analyses, quantified by FC, reveal the presence of damaged mitochondria and altered ER after Eto exposure. Both pre-treatments before drug, in particular iperglut, rescues mitochondria and ER functionality. This latter finding has been also confirmed by

TEM analysis which show preserved ER morphology in control $(\mathrm{K})$ and in iperglut before Eto-treated cells $(\mathrm{M})$. On the contrary, a dilated ER appears after Eto (L). WB analysis of $\mathrm{BIP} / \mathrm{Grp} 78(\mathrm{~N})$

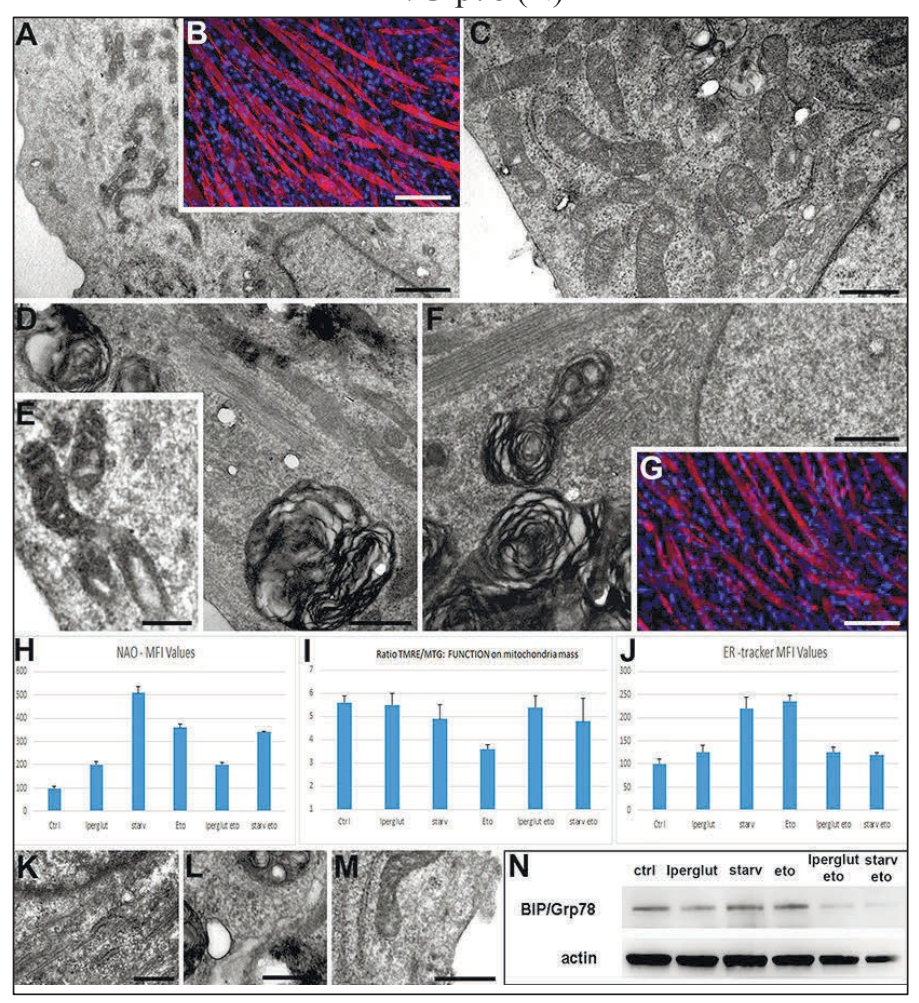

Figure 4

Bars: $1 \mu \mathrm{m}$ for A; $0.5 \mu \mathrm{m}$ for C, D, F, K, L, M; 200nm for E; $100 \mu \mathrm{m}$ for B and G 
Control and treated-samples after LC3 (A-F) and AO (G-M) staining observed by CLSM. LC3 dots are few in control cells

(A), localize as little puncta near plasma membrane after iperglut treatment (B) and their number increases in starved myotubes (C). After Eto exposure, LC3 staining appears as large dots diffuse in the cytoplasm and often observed between myonuclei (D). Iperglut or starvation administration before Eto reduces the size of LC3 puncta (E, F) which appear again localized along plasma membrane. Preserved lysosomes (red fluorescence) appears in control (G), iperglut $(\mathrm{H})$ and starved myotubes (I), stained with AO. Eto (J) induces an evident instability of lysosomal compartment (green fluorescence) which improves after iperglut $(\mathrm{K}, \mathrm{L})$ or starvation $(\mathrm{M})$ pretreatments before drug. AO quantification $(\mathrm{N})$, through $\mathrm{FC}$, confirms this behavior. In O, WB analysis of LC3, Beclin and p62 can be observed. Bars: $25 \mu \mathrm{m}$ for A, G-M; $10 \mu \mathrm{m}$ for B-F
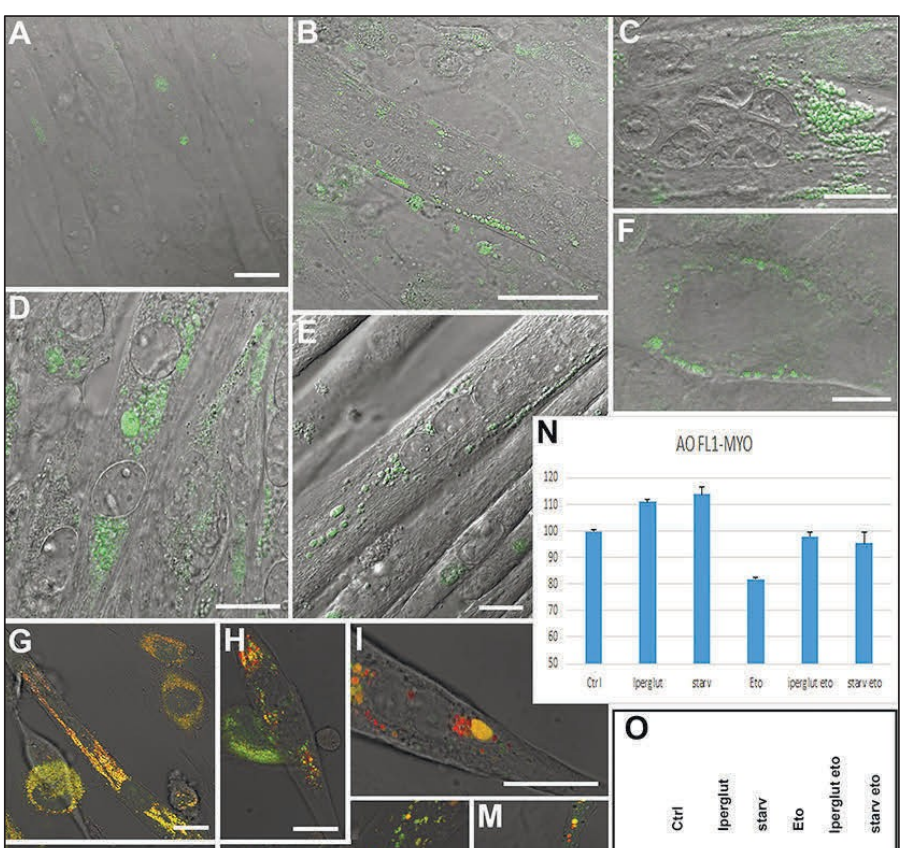

AOFLL-MYO
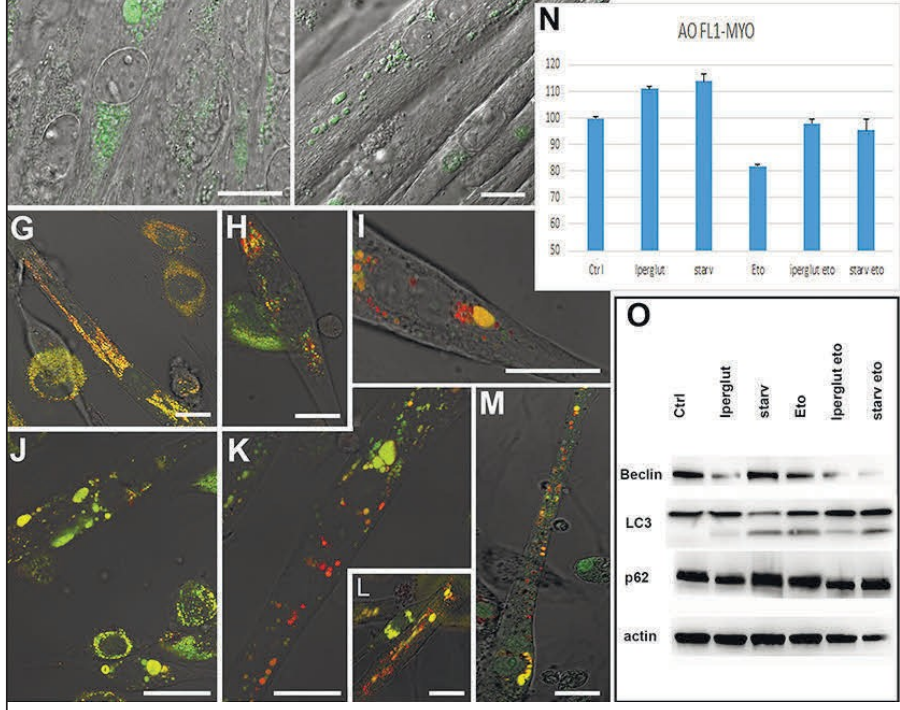

On the contrary, pre-treatments before chemotherapeutic drug exposure, maintained ER viability, as demonstrated by FC (Fig. 3J), TEM (Fig. 3M) and WB (Fig 3N) investigations.

Given the presence of a widespread autophagy, all samples have been stained with GFP-LC3 vector showing a slight presence of green spots in control condition (Fig 4A). Iperglutdifferentiated myotubes (Fig. 4B) displayed a peripheral localization of small LC3 dots. On the contrary, starved cells (Fig. 4C) showed a diffuse cytoplasmic localization of LC3

dependent degradation contributes to muscle atrophy and cachexia. On the other hand, inhibition of autophagic flux causes accumulation of protein aggregates and abnormal protein.

Accumulation of LC3 protein as large green spots (Fig.4D) appeared in Eto-treated cells, confirming TEM observations.

Both pre-treatments (Fig. 4E, F) seemed to have beneficial effects on Eto-treated myotubes: LC3 puncta appeared small and localized as described in the control, without the large accumulation noticed after drug exposure.

AO staining, evaluated by CLSM (Fig. 4G-M) and quantified at FC (Fig. 4N), showed a good morphology and preservation of autophagy-lysosome system in control (Fig. 4G), iperglut (Fig. 4H) and starved myotubes (Fig. 4I). It appeared downregulated after Eto exposure (Fig. 4J), suggesting a diffuse damage of autophagolysosomes and lysosomes. Iperglut (Fig. $4 \mathrm{~K}, \mathrm{~L}$ ) and starvation (Fig. 4M) treatments restored lysosomal functionality.

These findings have been then confirmed by WB analyses (Fig. 4O).

Beclin-1, a protein involved in the first phases of autophagy, appeared increased in starvation- and etoposide-treated cells compared with other conditions, suggesting an autophagic activation (45). In contrast, Beclin-1 expression decreased with either pre-treatment before drug exposure.

To analyze autophagy, the expression of the microtubuleassociated protein 1 light chain 3B (LC3B), in particular, of the lipidated isoform II (LC3B-II) has been investigated. WB showed that LC3B-I protein levels were not significantly modified in all experimental conditions, while LC3B-II protein levels appeared increased in starved myotubes and in Eto-treated samples. These findings suggested either autophagosome formation or reduced autophagosome turnover (46). On the other hand, in iperglut pre-treated cells before Eto exposure, an LC3B-II reduction could be observed.

Finally, p62/SQSTM1 expression, involved in selectively targeting protein aggregates to autophagosomes by simultaneously binding LC3B and ubiquitinated proteins, has been evaluated (47). p62, constantly removed by autophagy, is considered a good marker for autophagic vesicle turnover evaluation (48). p62 is degraded during autophagy and therefore its level should decrease when autophagy is induced.

High levels of p62 protein (fig. 4O) appeared in samples treated with starvation and Eto, suggesting autophagosome clearance impairment, probably due to exhaustion of the lysosomal degradative capacity. Iperglut administration before Eto induced p62 content reduction, indicating a reactivation of the autophagic flux, necessary to counteract Eto damage and, as a consequence, to maintain myotube homeostasis.

\section{Discussion}

Autophagy protects cells from stress (49) and plays a crucial role in the regulation of homeostatic processes $(50,51)$ by favoring the turnover of cell components and the clearance of damaged organelles through the autophagic-lysosomal pathway (52). It is known that excessive activation of autophagy-

organelles, leading to myofiber degeneration $(53,54)$.

In this study, two different culture conditions (iperglut or starvation) have been investigated in terms of restoring 
affected myotubes exposed to Eto. This chemical, as revealed by ultrastructure and cytofluorimetric analyses, induces mitochondrial damage, ER alteration, cardiolipin oxidation and accumulation of abnormal vacuoles in differentiated skeletal muscle cells. It induces also an increase of BTP, a known marker of ER stress: this parameter probably reflects a higher level of ROS, also confirmed by the presence of a mitochondrial population characterized by oxidized cardiolipin and loss of their functionalily (55)

Moreover, CLSM observations reveal in Eto-treated myotubes an increase of LC3 puncta, absent in control samples, as fluorescent abnormal dots and an alteration of acid organelles stained with $\mathrm{AO}$, which reflect the lysosomal instabilily. WB analysis show that chemotherapeutic drug induces an increase of two known markers of autophagosome formation such as Beclin1 and LC3-II; in additon, p62 expression results up-regulated in Eto-treated samples in agreement with several studies that, in general, have documented a p62 increase under oxidative stress conditions, thus indicating its accwnulation inhibits the correct autophagic flux $(56,57)$.

Pre--treating myotubes before chemical exposure with iperglut, and to a lower extent with starvation, improves cell morphology: restored mitochondria, ER, and preserved lysosomes can be detected. Moreover, WB analysis evidences in iperglut or starved myotubes before drug, if compared with Eto-treated cells, a down-regulation of Beclin1, LC3IJ and p62 expression. p62 levels reduction indicates an increased autophagic flm: $(58,59)$, confirmed by AO staining, which leads to an improvement of lysosomal compartment efficiency.

The autophagy-lysosomal pathway is an important player implicated in the turnover of organelles and long-lived proteins, as well as in the clearance of damaged cell component<:> and the degradation of cell material in order to allow energy supply and cell survival during starvation and stress (60). In skeletal muscle, autophagy is a highly regulated process that can be beneficial or deleterious, depending on its activation levels and on cellular environment. Therefore, we could interpret our findings assuming that in Eto-treated cells, as well as in starved myotubes, the increase of Beclin1 and the LC31I indicate induction of autophagy. On the other and, the increase of p62 suggests a defective autophagosome clearance and turnover. This interpretation is in agreement with Masiero et al. 2010 (61) who demonstrated that an impairment of autophagic flmc as well as its inhibition leads to protein accumulation, contributing to muscle degeneration.

Our findings also show that a modulation of culture conditions before chemical treatment, in particular iperglut administration, could exert a protective role in rescuing muscle fiber from degeneration induced by a chemotherapeutic trigger.

Tn conclusion, L-gl utamine supplementation could be considered as a potential inducer of autophagic reactivation by maintaining skeletal muscle homeostasis nnder oxidative stress conditions and in some severe muscle disorders, including aging, characterized by an accumulation of autophagosomes, due to lysosomal fnnction defects.

Acknowledgments: This work has been possible thanks to the DISB 2017 Enhancement Project of Urbino University. We would like to thank the researchem of the Translational Cardiomyology Laboratory (KU Leuven) for suggestions and support in IF analyses.

Conflict of interest: No conflict of imerest;

\section{References}

I. Sandri M, Colel to L, Grumati P, Bonaldo P: $\mathbf{J} \backslash$ lisregulaion of auloph;gy and prolein degradation systems in myop<thies and muscular dystrophies. J. Cell Sci 2013, 126: 5325---B. htlps:/ldoi. orgl10.1242/jcs.114041.

2. Damrauer JS, Stadler IviE. Acharyya S, Baldwin AS. Couch 11E, Guttridge DC: Chemotherapy-induced muscle wcr;ting: associ<tion with NF-xB and cancer cachexia Eur JTransl Myol2018, 28(2): 7590. https:ildoi.org110.4081/ejtm.2018.7590.

3. Lee Y, Lee HY, Gustafsson AB: Regulation of autoph;gy by metabolic and stress signaling pathways in the heart. J Cardiovasc Pharmacol 2012. 60: 118-124. doi: 10.1097IFJC.ObO13 e318256cddO.

4. Levine B, Kroemer G: Autophagy in the pathogenesis of disease. Cell2008, 132(1): 27--42. https:1I doi.orgl10.1016/j. cel1.2007.12.018.

5. Mizushima N, Levine B, Cuervo AM, Klion<Jky D.T: Autoph;gy figh1s di<Jea<;e through cellular self-digestion. Nature 2008, 451(7182):1()59-1075. doi: 10.1038/nature06639.

6. Park YE, Hayashi YK, Bonne G, Arimura T, Noguchi S, Nonaka I, Nishino 1: Autoph;gic degrad<tion of nuclear components in mammalian cells. Autophagy 2009, 5(6): 795---804. https:/1 doi. org110.41611auto.8901

7. Saha S, Panigrahi DP, Patil S. Bhutia SK: Autophagy in health and disease: A comprehensive review. Biomed Pharmacother 2018. 104: 85-495. https:/ldoi. org/10.1016/j. biopha2018.05.007.

8. Lu SZ, Harrison-Findik DD: Autophagy and cancer. World J Bioi Chem 2013, 4(3): 64---70. doi: 10.4331/wjbc.v4.i.164.

9. Henson E, Chen Y, GibsonS: EGFR filllily membem' regul<tion of autophagy is at a crossroads of cell smvival and death in cancer. Cancers (Basel) 2017,9(4): pii: E27. https:Jidoi. org110.3390ic anc er59040027.

10. Kang YH, Cho MH, Kim JY, Kwon MS, Peak JJ, Kang SW, Yoon SY, SongY: Impaired macrophage autophagy indnces systemic insulin resistance in obesity. Oncotarget 2016, 7(24): 35577-35591. https:1/doi.org/10.18632/oncotarget.9590.

11. Cheung ZH, Jp Nl': Autoph<-gy deregul<tion in neurodegenerative di<Jeases -- recen1 advances and future pempectives. J Neurochem 2011, 118(3): 317-325. hrtps://doi. otg/10.111lij.1471-4159.2011.07314.x.

12. Settembre C, Fraldi A Jahreiss L, Spampanao C, Venturi C. Medina D, de Pablo R. Tacchetti C, Rubinsztein DC, Ballabio A: A block of autophagy in lysosomal storage disordeJS. Hum Mol Genet 2008, 17(1): 119-29. https:1/doi.org/10.1093/hmg/ddm289.

13. Fanzani A Zanola A Rovetta F, Rossi S, Aleo MF Cisplatin triggm atrophy of skeletal $\mathrm{C} 2 \mathrm{C} 12$ myotnbes via impairment of Akt signalling $\mathrm{p}<$ thway and suh'lequent increment activity of proteasome and autoph $\mathrm{O}$ )

$2011,250(3), 312--321$.https:1/doi.org/10.1016/j.taap.2010.11.003.

14. Stacchiotti A Favero G. Giugno L, La<iazza A Reiter RJ. Rodella LF, Rezzani R: MitodJOndrial and metabolic dysfunction in renal convoluted lubules of obese mice: protectiverole of mel<tonin. PLoS One 2014, 9(10):el11141. hrtps://doi.org/10.1371/ joumal.pone.Oll1141.

15. Saln"i S, Burattini S. Baldassaui V, B $<$ ttistelli M. Canoni'o B, Valmori A PapaS, Falcieri E: 'The peculiar apoptotic behavior of skeletal muscle cells. Histol Histopathol 2013, 28(8), 1073-1087. doi: 10.14670/Illi-28.1073.

16. Salucci S, Baldassaui V, Canonico B, Bur $<$ ttini S, Battistelli M, Guescini M, Papa $\mathrm{S}$, Slocchi V, Falcieri E Melatonin behavior in restoring chemical dam;ged $\mathrm{C} 2 \mathrm{Cl} 2$ myoblasts. Microsc Res Tech2016: 79(6), 532-540. doi: 10.1002/jemt.22663.

17. Salu,ci S, BaJtistelli M, Baldassan-i V, Burini D, Falcieti, E, Buratlini S: Mel<tonin prevents mitochondrial dysfunctions and death in differentiated skeletal muscle cells. MicroscRes'Tech2017, 80(11): 1174-1181. doi: 10.1002Jjemt.22003.

18. Conte E. Camerino GM, Mele A. De Bellis M, Piemo S, RanaF, Fonzino A. Caloiero R, Rizzi L, Bresciani E, Ben Haj Salah K, Fehrentz JA, Martinez J, Giustino A MariggiO MA. Coln"iaM, Tri,arico D, Lograno 11D, De LucaA, Tomello A Conte D. Liantonio A: Growth hormone secretagogues prevent dysregulaion of skeletal musde calcium homeostasis in a rat model of 'ispl $<$ tin-induced ca,hexia $\mathrm{J}$ Cachexia SarcopeniaMusde, 2017, 8(3): 386--404. hrtps:/1 doi.org/10.10021jcsm.12185.

19. Douglas E, McMillan DC: Toward-; a simple objective frantework for the inves ligation and tre $<$ tment of cancer cachexia: the Glasgow Prognostic Score. Cancer Treat Rev 2014, 40::6): 685-91. https:/1 doi. orgl10.10161].ctrv.2013.11.007.

20. Gaurav K, Goel RK, Shnkla M, Pandey M: Glutamine: a novel approach to 
dlemotherapy -induced toxicity. Indian $\mathrm{J} J \backslash \cdot$ led Paedi<1 r Oncol2012. 33(1): 13---20. doi: $10.4103 / 0971-5851 . \% \% 2$.

21. Yoshida S. Kaibara A. Jshib $<$ tJhi N. Shirouzu K: Glutantine supplemen 1 ation in ,an,er patients. Nutrition 2001. 17(9):766-768 https://doi.org/10.1016/S08999007(01)0()529-3

22. GiJVen M. Dug dale HF. O.Vens DJ. Hughes DC. Stewillt CE. Sharples AP 1-glutan1 ine improves skeletal musde cell differentiation and prevents myotube atrophy after cytokine (tnf-a) stress via reduced p38 mapk signallramduction. J Cell Physiol 2016. 231(12): 2720-2732. https:i/ doi.org/10.1002Jjcp.25380.

23. De Palma C. PerroHa C. Pellegrino P. Clementi E. Cetvia D: Skeletal muscle homeostasis in duchenne muscular dystrophy: modulating autophagy $<\mathrm{t}$ a promisiug 1herapeutic s1rategy. Front Aging Neurosci 2014. 6: 188. htlps:lldoi.orgl10.33891 fn i.2014.00188.

24. Battistelli M. Salucci S. Olivotto E. Facchini A. Minguzzi M. Guidotti S. Pagani S. Fla1nigni F. Borzl RM. Facchini A. Falcieri E: Cell death in huma11 articular chondrocyte: a morpho-fnnctional study in micromass model. Apoptosis 2014. 19(10): 1471---1483. doi: 10.10071s10495-.014-1017-9.

25. Burattini S. Salucci S. Baldassarri V. Accorsi A. Piarti E. Madrona A. Espartero JL. Candiracci M. Zappia G. Falcieti E: Anti-apoptotic adivity of hydroxytyrwol and hydroxytyrosyllaurate. Food Chem Toxicol 2013. 55: 248-256. https:i/doi. org110.10161j.fct.2012.12.049.

26. Saluc'i S. Burattini S. Falcieri E. Gobbi P: Three-dimensional apoptotic nudear behavior analyzed by means of Field Emission in Lens Scanning Electron Microscope. EurJHisto,hem2015. 59(3): 2539. doi: 10.40811 ejlL2015.2539.

27. Salucci S. Battistelli M. Burattini S. Squillace C. Canonico B. Gobhi P. PapaS. Fal,ieri E: C2C12 myoblast sensitivity to different apoptotic chemical triggem. Minon 2010. 41(8): 966-73. https:/Idoi.orgl10.10161j.microll2010.07.002

28. Bur<ttini S. Rtli<Jtelli M. Codenotti S. Falcieri E. Fanzani A. Salucci S: Melatonin action in tumor skeletal muscle cells: an ultr<Etructural study. Acta Histochem 2016. 118(3): 278-285. doi: 10.1016/j.ac1his.2016.02.004.

29. Costamagna D. Quartrocelli M. Villl Tienen F. Umans L. de Coo IF. Zwijsen A. Huylebroeck D. Sampaolesi M: Smadl/5/8 are myogenic regulators of mmine and human mesoillJgioblasts. J Mol Cell Bioi 2016. 8(1): 73--S7. https:/idoi.orgl10.1093i jmcb/mjv059.

30. Luchetti F. Ca1wnico B. Mannello F. MasoniC. D'Emilio A, B<ttistelli M, Papa S, Falcieri E: Melatonin reduces early changes in intramitochondrial cardiolipin during apoptosis in U937 cell line. Toxicol Jn Vitro 2007, 21: 293---301. ht1ps:/ldoi. org110.10161j.tiv.20()5.08.003

31. Canonico B, Campana R, Luchetli F, Arcangeletti M, Betti M, Cesarini, E, Ciacci C, Vittoria E, Galli L, PapaS, Baffone W: Campylobacter jejuni 'elllys $<$ tes differently target mitochondria and lysosomes on HeLa cells. Apoptosis 2014, 19: 1225-1242. https:/idoi. orgi10.1007is1049.

32. Ehrenberg B, Montana V, Wei !viD, Wuskell JP, Loew LM: Membrane potential can be detelmined in individual cells from the nermtian distribution of $\mathrm{c}<$ tionic dyes. Biophys J 1998, 53: 785-794. https:ildoi.orgi10.10161S0006-3495(88)83158-8.

33. Luchetti F, Betti M, Canonico B, Arcangeletti M, Ferri P, Galli F, Papa S: FRK MI $\backslash P K$ activation mediates the antiapoptotic signaling of mel<tonin in UVB-stressed U937 cells. Free Radic Bioi Med 2009, 46: .B9---351. ht1ps://doi.org110.1016/j. freeradbiomed.2008.09.017.

34. Hogg RC, Adams DJ: An atp-sensitive $\mathrm{k}(+)$ conductance in dissoci<ted nemones from adult $\mathrm{r}<\mathrm{t}$ intracardiac ganglia J. Physiol2001, 534: 713-720. https:ildoi.org/10.11111 j.1469-77<J3.2001.00713.x

35. Gh $<$ tJemi M. Khodaei N, Salari S, Eliassi A. Saghiri R: Gating behavior of endoplasmic reticulum pot $<\mathrm{t}$ Jsium channels of rat hepatocytes in diabetes. Iran. Biomed. J2014, 18: 165---172. doi: 10.6091! ibj.B082.2014.

36. Thibodeau MS, Giardina C. Knecht DA. Helble J, Hubbard AK: Silica-induced apoptosi<; in mome alveolar macrophages is initiated by lysosomal enzyme activity. Toxi,ol Sci 2004, 80(1), 34--48. https:/i doi.orgl10.1093itoxs, i/kfl1121

37. Chen Y, Azad MB, Gimon SB: Methods for detecting autophy autophagy-induced cell death. Cald Physiol Phannacol2010, 88: 285-295. https:/idoi. org/10.1139/Y 10-010.

38. Canonico B, Cesarini E. Salucci S, Luchetti F, Falcieri E. Di Sario G. PalmaF, PapaS: Defective Autophagy, Mitochondrial Clearance andLipophagy in Niemann-Pick Type B Lymphocytes. PLoS One 2016, 11(10): e(J165780. hJtps:1ldoi.org110.1371ljournal. pone. 0165780

39. Salucci S, Bur $<$ ttini S, Buontempo F, Mat1elli At|1, Falcieri E, Batli<Jtelli M: Protective effect of different antioxidantents in $\mathrm{U} \backslash \mathrm{iB}$-inadiated $\mathrm{ker}<$ tinocytes. Eur J Histochem 2017, 61(3), 2784. doi: 10.4081!ejh.2017.2784.
40. Gabillard JC, Sabin N, Paboeuf G: Tn vitro characterization of proliferalion and differentiation of trout satellite cells. Cell Tissue Res. 2010, 342(3):471-7. doi: 10.1CKJ71 )0441-010-1071-8.

41. Kwak111. Choi HE, Cheon HG: 5-LO inhibition ameliorates palmiti' acid-inducedER stress, oxidative stress and imulinresistance viaAMPK activation in murinemyotubes. Sci Rep 2017, 7(1): 5025. doi: 10.10381s41598-017-05346-5.

42. Lee J, Ozcan U: Unfolded protein response signaling and metabolic dise $<$ tJes. J Bioi Chem2014. 289(3): 1203-1211. doi: 10.1074ijbcR113.534743.

43. Foti DM. W elihinda A, Kaufman R.J. Lee AS: ConseJV<tion and divergence of the ye $<$ tJt and mantmalian unfolded protein respo! $1<$ Je. Adivation of specific mannnalian endoplasmic reticulum stress element of the grp78/BiP promoter by yeast Hacl. J Bioi Chern 19'>' 9, 274(43): 30402---304®) doi: 10.1074ijbc.274.43.30402

44. Bertolotti A, Zhallg Y, Hendemhot LM. Hal-ding HP, Ron D: Dynami' interaction of $\mathrm{BiP}$ and ER stress transducem in the tmfolded-protein response. $\mathrm{N}<\mathrm{t}$ Cell Bioi 20CXJ, 2(6): 326-332. doi: 10.1038/35014014.

45. Aversa Z, Pin F, Lucia S, PennaF, Verzaro R, Fazi M, Colasante G, Tirone A, Rossi Fanelli, F, Ran1ac,ini C, Costelli P, Mus,aritoli M: Autophy skeletal muscle of cachectic cancer paients. Sci Rep 2016. 6: 30340. doi: 10.1038/ srep30340.

46. Tanida I, Ueno T. Kominami E: LC3 conjugation system in mammalian autophagy. Int J Biochem Cell Biol 2004, 36(12) :2503--18. https://doi.org/10.1016/j. bioce1.2004.05.009.

47. Kirkin V, McEwan DG, Novak 1, Dikic I: A role for ubiquitin in selective autophagy. Mol Cell2009, 34(3): 259--69. https:i/doi.org/10.1016/j.molce1.2009.04.026.

48. Klionsky DJ et al: Guidelines for the use and interpretation of assays for monitoring autophagy (3rd edition). Autophagy 2016, 12(1):1-222. doi: 10.1080115548627 .2015 .1100356

49. Sailoh T, Ak.ira S: Regulation of innate immune responses by autophagy-relaled proteins. J Cell Biol2010, 189(6):925-935. http:// doi.org110.1083ijcb.201002021.

50. Lee JA, Gao FB: ESCRT, <rutoph<-gy, and frontotemporal dementia. HMB Rep 2008, 41(12): 827--S32. doi: 10.10161j.freeradbiomed.2017.07.017.

51. Levine B, Mizushima N, Virgin HW: Autophagy in immunity and inflammation. Nature2011, 469(7330):323-335. doi: 10.1038/nature09782.

52. Grumati P, Coletto L, Sabatelli P, Cescon M, AngelinA, Bert gia Urciuolo A, Tlepolo T, Merlini L, Maraldi G'M, Bernardi P, Sandri M. Bonaldo P: Autophagy is defective in collagen VI muscular dystrophies, and its reactivation rescues myofiber degeneration. Na1 Med 2010, 16(11), 1313--20. doi: 10.1038/ nm.2247.

53. Romanello V, Sandri M: Mitochondrial Quality Control and Muscle Mass Maintenance. Front Physio12016, 6:422. doi: 10.3389/fphys.2015.00422.

54. Pollock N, Staunton CA, V<tJilaki A, McArdle A, Jackson 111: DeneiYated muscle fibem induce mito,hondrial peroxide gener $<$ tion in neighboring innelv $<$ tedfibem: Role in muscle aging. Free Radic Bioi Med 2017, 112: 84-92. https://doi.org!10.1016/j. freeradbiome d2017.07.017.

55. Fiene N. Barbe C, Gilson H. Deldicque L. Raymackem JM, Francaux M: Activation of ER s1ress by hydrogen peroxide in $\mathrm{C} 2 \mathrm{C} 12$ myotubes. Biochem Biophys Res Commnn. 2014. 450:1): 459--63. https:1/doi.orgl10.1016/j.bbrc.2014.05.143.

56. Zheng YT, Shahnazari S, Brech A, Lamark $T$, Johansen $T$, Brumell JH: The adaptor protein p62iSQSTM1 targets ilNading ba,teria to the autophagy $\mathrm{p}<$ thway. J Immnnol 2CK19, 183(9): 5909-16. https://doi.org/10.4049/jimmuno1.09W441.

57. Park SY, Snn EG, Lee Y, Kim MS, Kim JH, Kim WJ, Jung JY: Autophy plays a protective role against hypoxic stress in human dental pulp cells. J Cell Bio,hem2018. 119(2): 1992-2002. https:1/doi.org/10.1002/jcb.26360.

58. Bj!))rkl)y G, Lamark T. Pankiv S, 0veiYatn A Brech A, Johansen T: Monitoring autophagic degradation of p621SQSTM1. Methods Eneymo12009, 452: 181--97. https: $/ i$ doi. orgi 10.10161S0076-6879(08)03612-4.

59. Lesmana R, Sinha RA, Singh BK, Zhou .J, Ohba K, Wu Y, Yau WW, Bey BH, Yen PM: Thyroid Hormone Stimulation of Autophagy Is Essential for Mitochondrial Biogenesis and Activity in Skeletal Muscle. Endocrinology 2016, 157(1):23-38. https:Jidoi. orgl10.1210ien.2015-1632.

60. Glick D, Barth S, Macleod KF: Autoph y: $\mathrm{P}<$ tho12010, 221(1). 3-12. https:/ldoi.org110.10021p $<$ th2697.

61. $\mathrm{M}<\mathrm{t}$ Jiero $\mathrm{E}$ Sandri M: Autophagy inhibition induces < trophy and myopathy in adult skeletal mllides. Autophy 